\title{
The Principle of Liberal Imperialism: Human Rights and Human Freedom in the Age of Evangelical Capitalism
}

\author{
Jeff Noonan University of Windsor
}

\begin{abstract}
Résumé
Le présent article s'attache à démontrer l'incohérence conceptuelle du principe qui soustend l'impérialisme libéral. Selon ce principe, les nations libérales se doivent d'intervenir chez les nations non libérales en réaction à des violations systématiques des droits de la personne, afin de créer les conditions permettant à la population de devenir un agent de contestation. Toutefois, la légitimité d'une intervention de ce type repose sur un présupposé qui nie en fait ce qui est censé la justifier : la capacité des opprimés à contester. Ce manque de cohérence amène l'article à esquisser, en conclusion, une conception matérialiste de l'agent de contestation, où prime la capacité des populations opprimées à trouver des sources internes de critique et de transformation sociale.
\end{abstract}

\footnotetext{
Abstract

The paper argues that the principle that underlies liberal imperialism is conceptually incoherent. The Principle of Liberal Imperialism claims that liberal nations have a duty to intervene in non-liberal nations in response to persistent human rights violations for the sake of creating the conditions in which the agency of the population can be realized. The legitimacy of such interventions, however, is rooted in a presupposition that denies the very agency of the oppressed in whose name the intervention is justified. In response to this incoherence the paper concludes with the outline of a materialist conception of agency that prioritises the capability of oppressed populations to find internal resources of critique and social transformation.
} 


\section{Introduction}

It is ironic, given George W. Bush's evangelical antipathy towards all things "liberal" that his attempt to justify the second Iraq war as a battle for human rights and democracy echoes cosmopolitan liberal arguments in favour of military intervention against authoritarian regimes. The cosmopolitan liberal argument of course does not necessarily favour unilateral military action by the United States, but its commitment to armed intervention by the community of 'democratic' nation states betrays an underlying unity of principle with the rhetorical strategy now being adopted by the American administration. Michael Ignatieff, for example, defends military intervention to effect regime change as a 'lesser evil' (2004: 160-67). David Held (2004), generally a more aggressive critic of contemporary global relations, posits the need for a reformed United Nation's security apparatus that would make it possible to democratically legitimate the invasion of states found to be in serious and long-term breach of global human rights standards.

In this paper I am interested in teasing out this underlying unity of principle, not as a reductio ad absurdum of cosmopolitan liberalism, but rather to disclose the conceptual incoherence of what I will call the Principle of Liberal Imperialism (PLI). My essential aim in so doing is to reveal a fundamental contradiction between the principled value of human freedom in whose name 'human rights wars' are purportedly launched and the denial in practice of the freedom and agency of the citizens of the targeted nation. Once the conceptual incoherence of the PLI has been made clear it will become apparent that its contradictions stem from deeper inadequacies in the liberal conceptualization of human rights. I will conclude the argument by laying bare these inadequacies and defending an alternative materialist interpretation of the foundations of human freedom. This alternative shifts the focus from an asserted duty of 'democratic' nation states to create free institutions for oppressed populations to the capacity of those populations to transform their own societies themselves.

\section{The Principle of Liberal Imperialism}

The immediate context for this investigation of the coherence of the PLI is the effort of the American administration to justify their invasion of Iraq as essential to the interests of the Iraqi people themselves in securing the social conditions of freedom. However, the PLI cannot be understood simply as a rhetorical tactic of particular administrations. It is a general principle running beneath liberal conceptions of the relationship between Western liberal-capitalism and the non-Western, non-liberal world. I will first state the principle clearly and then reconstruct the presuppositions that must be in place in order for it to take on the appearance of plausibility.

The collapse of the Stalinist societies of Eastern Europe had the dual effect of discrediting all forms of socialism as a real alternative to capitalism and establishing the liberal form 
of democracy as the only real form of democracy historically possible. In short, the new historical conditions after 1989 made it appear that liberal-capitalist democracy was the only form of a free society worth fighting for because it was the only form of free society possible. These events seemed to reconfirm an older understanding of Western social organization as the necessary goal of all social development. On this assumption all other modes of social organization appear as historically retrograde in a quite precise sense. Since non-liberal forms of social organization are assumed to rest upon irrational forms of authority, such that people trapped within in them are kept in place by archaic beliefstructures, it seems to follow that they are incapable of freeing themselves unless rational liberal ideas are imported into them by the agency of Western powers.

The Principle of Liberal Imperialism (PLI) can be discovered by reflecting upon what ties together the classical liberal understanding of the nature of non-liberal societies to the post-1989 form of liberal-capitalist triumphalism. It can be formally defined as follows: The commander in chief of a militarily dominant nation or a self-selected collective of democratic nations is legitimately entitled to order his or her armed forces or a collective of the armed forces of democratic nations to invade the internationally recognized sovereign space of another nation when that nation is a known violator of human rights, even in the case that: 1) there is no authorization in international law for the invasion, 2) the geo-strategic interests of the militarily dominant nation or collective of nations and its (their) historical rivals can be demonstrated to be the structural cause of the history of human rights violations, and 3) no independent, organized, and recognized body of citizens in the oppressed nation has called for an invasion as a means of their liberation.

The generality of the principle is obtained by abstraction from the concrete history of the last two centuries of imperialist conflict. The first historically significant version of this principle was the product of British, not American imperialism. Recall, for example, J.S. Mill's assertion that Britain was entitled to rule India since India, 2500 hundred years of complex cultural, artistic, political, mathematical, scientific, and philosophical history notwithstanding, was in its "nonage" (Mill, 1975: 11). ${ }^{1}$ Since the structure of Indian society was assumed to be such that Indians themselves could not understand their own oppression (that is what he means by 'nonage') their only hope was to acquiesce in the imposition of British forms of government. Like children unable to understand what is good for them, Indian people could only assume control of their own affairs once they had emerged from a period of tutelage. One can see exactly the same sort of reasoning at work in Iraq today. American commanders continue to maintain that they cannot withdraw troops until Iraqis have become politically and militarily mature enough to assume responsibility for their own affairs.

${ }^{1}$ To be fair it should be noted that Marx did not essentially disagree with Mill on this point. (Marx, 1972: 35-41, 81-87). For a deeper discussion of the ironies produced by this agreement see Noonan (1997: 1000-1011). 
The conceptual arc that links the classical and contemporary forms of the PLI is thus established and maintained by a certain presupposition without which the principle does not make sense. If, as the principle maintains, liberal societies are duty bound to invade an oppressive but nevertheless sovereign nation if the invasion is undertaken in the name of the oppressed people (but without their asking to be invaded), then it must be presupposed that the oppressed themselves cannot, even in principle, free themselves from this oppression. Unless that presupposition is granted there would be no reason for the invasion. Since the invasion is undertaken in the name of enforcing the human rights of the oppressed, it would be wholly unnecessary if, alternatively, it were presupposed that they could, through their own struggles, overcome the tyranny under which they suffer.

Thus, without the presupposition of the political or historical backwardness and incompetence on the part of the oppressed, the PLI would make no sense. In fact, it is so important to the plausibility of the PLI that it could be called quasi-transcendental to indicate its constitutive but historically ungrounded function. ${ }^{2}$ That is, the presupposition of the political backwardness of the oppressed tends to ignore or rule out evidence to the contrary and to always suppress the contribution that major imperialist powers have made to the so-called backwardness from which the oppressed must be rescued. Again the current situation in Iraq is a paradigmatic example of the point I am making. The demonization of Hussein in the run up to the war suppressed the historical cooperation between the Reagan administration and Hussein's brutal regime. It also ignored the fact that Hussein was supported in his rise to power, encouraged in his destruction of the progressive elements of the original $\mathrm{Ba}$ 'ath movement, its anti-imperialism and its investment of oil wealth in the development of region-leading social infrastructure, and his abuses overlooked so long as he was a trusted ally against Iranian regional power (Ali, 2002).

Thus the hegemony of the PLI depends both upon definite historical conditions and a selective and one-sided understanding of the cultures within which its political prescriptions are enacted. The historical conditions upon which it depends occur whenever there appears to be no alternative goal to social development other than liberalcapitalism of a Western form. When Mill was writing in the mid- to late-nineteenth century the alternative to liberal-capitalism could only appear to be continued stagnation under archaic and authoritarian cultural forms. The subsequent emergence of the various modalities of socialism offered alternatives for social development. With the collapse of plausibility of the various socialist alternatives, the conditions in which the PLI first gained plausibility have returned.

\footnotetext{
${ }^{2}$ I am using 'transcendental' in Kant's sense. A transcendental principle was an a priori structure of consciousness which enabled definite empirical operations. The principle at issue here is 'quasi' transcendental since, while it is a priori and grounds the possibility of empirical judgements in particular cases, it is not a property of subjective consciousness but a presupposition of a definite political theory.
} 
But the appearance of there being no alternative to liberal-capitalism is only one half of the conditions necessary for the hegemony of the PLI. It must also be assumed that the indigenous culture itself contains no immanent resources for progressive selftransformation. In order to maintain the plausibility of this assumption the popular media and public intellectuals must construct the culture and history of the target population as inherently incapable of producing citizens capable of critical self-reflection and conscious planning. Thus, to cite the case of Iraq once again, Western citizens are told again and again that in addition to the historical legacy of Ba'athism Iraq's democratic transformation is impeded by its tribal history, by the atavistic irrationality of ethnic ties, and by the way in which the Ba'ath party historically exploited those divisions. There is of course some truth to this argument, but my point is that it is only one side of the truth. Ba'athism itself was a product of anti-colonial democratic self-organization in the Arab world in the late 1950s and early 1960s and demonstrated precisely the capacity for internal self-organization and self-transformation whose denial is the necessary condition of plausibility for the application of the PLI to Iraq (and perhaps next Syria, the other major centre of Ba'athism).

This second set of conditions trades upon a four centuries old assumption of what Charles Mills has called the 'system' of white supremacy. This system, Mills argues, is rooted in deliberate ignorance of the complexities, nuances, and forms of social intelligence internal to non-white and non-Western cultures (Mills, 2003). It might be suggested that not all the targets of the PLI are non-white cultures; a key case being the NATO led air-war against Serbia in 1999. While it is indeed true that the PLI is not applied exclusively to the nonwhite world, it is also true that when it is applied to white Western cultures they will be interpreted according to quasi-racist ethnic caricatures that reveal them to be lacking some essential element of liberal social intelligence. Thus the Serbs were uniquely accused of exclusionary and embryonically violent pre-modern ethnic loyalty. In the period of intense inter-imperialist rivalry between Britain and Germany, the liberal elements of German culture and its profound philosophical contributions to the understanding of the nature and conditions of individuality and freedom were suppressed in order to present Germans as culturally programmed for conquest and domination. These examples could be multiplied but the point should be clear. The hegemony of the PLI depends upon historical conditions in which there appear to be no historical alternative to liberal capitalism and the cultures targeted by the PLI must be constructed in the Western political imagination as in principle incapable of discovering internal resources for self-transformation.

Whenever these conditions are satisfied the PLI gains hegemony. The weakening of national sovereignty by the contemporary forces of capitalist globalization further strengthens its appearance of plausibility. Alongside the opening of borders to direct foreign investment, globalization has opened human consciousness to the conditions of 
life around the globe. This opening of consciousness has awakened people to the reality of human suffering in other parts of the globe. To liberals this suffering is understood to result from the violation of the human rights of the oppressed population, and the solution therefore appears to be protection of their human rights. Since the oppressed culture is understood to be opposed by its historical nature both to human rights and the capability to generate internal forces for change the only solution appears to be some form of forcible intervention. If the oppressed cannot defend themselves against human rights abuses, and human rights abuses negate the legitimacy of national sovereignty, then it seems to follow that a major power that respects human rights is not only justified, but indeed mandated, to invade for the sake of rescuing the oppressed from their plight.

\section{The Conceptual Incoherence of the PLI}

I have argued that the PLI justifies intervention in the case where an authoritarian government persistently violates the human rights of its citizens. The justification relies upon the assumed incapacity on the part of a population of a non-liberal culture to organize and transform its social relations itself. Thus, in order to become agents, the PLI assumes, a liberal power or powers must interpose themselves between the citizens and the ruling powers, removing the latter to make social space for the agency of the former. Having set out the structure, presuppositions, and process by which the PLI gains hegemony, let me now turn to the task of examining its conceptual coherence.

Ironically, the critique of the PLI must begin from the very idea of agency essential to the justification of the PLI itself. In fact, it was one of the liberal tradition's most penetrating philosophical minds, Immanuel Kant, that provided the formal basis for my critique. Writing at a time when it was clear that there was nothing democratic about traditional European culture, Kant saw right through the aristocratic and theocratic argument that certain groups of human beings were not yet 'ripe' for the freedom that eighteenth century liberals demanded. Kant argued:

I cannot admit the expression, used by even intelligent men: A certain people ... is not yet ripe for freedom; the bondsmen of a landed proprietor are not yet ripe for freedom; and thus men in general are not yet ripe for freedom of belief. According to such a presupposition freedom will never arrive; for we cannot yet ripen to this freedom unless we are already set free-we must be free to use our faculties purposivelyin freedom [and] we never ripen to freedom except through our own efforts, which we can make only when we are free (Quoted in Arendt, 1992: 48).

The essential point that I want to draw out of this passage is Kant's insistence that 'ripening' to freedom can only ever take place through the agency of the people who are 'ripening.' What he argues is that ripening towards freedom must be the free act of people 
themselves issuing from an essential and underlying human freedom anchored not in this or that culture but in the self-reflective and spontaneously creative nature of the species itself. To argue that a people must pass from one form of tutelage to another is to in fact deny in essence that they are capable of the freedom in whose name the tutelage is undertaken. This point must be carefully unpacked.

The deep point implied by Kant's argument is that if freedom is essential to ripening towards freedom, then it follows, however paradoxical it may sound, that the means by which a group is liberated from oppression is also essential. In other words, a free people must free itself from oppression; it cannot become free as the passive object of a foreign power's activity. The apparent paradox may be resolved by distinguishing an essential freedom that attaches to human subjecthood as such, and the freedom that is a function of institutional forms brought into conformity with this essential freedom. Kant himself, however, provides only the formal grounds for the critique of the PLI, not its necessary content. The problem is that for Kant freedom is just a moral fact about individual human beings, grounded in our capacity to govern our bodily desires. As such, freedom is opposed to our material nature and can never become the fully realized principle of social life as a whole (Kant, 1987). While the trajectory of Kant's philosophy is towards a conception of human social relations as legitimate only to the extent that they make possible the fullest realization of human freedom, the historical context in which he worked made it impossible for him to adequately theorize what those social conditions were (Goldmann, 1971). In particular, Kant was blind to the way in which market relations (then just beginning to emerge as the dominant force of social organization) functioned as essential impediments to a fully free society.

Thus we must shift our focus from Kant to Marx to fully grasp what it means to distinguish between an essential form of human freedom and the social forms in which this freedom is either realized or denied. To argue that human beings are essentially free is not only to argue, as Kant does, that our rational nature is a power that enables us to choose the moral laws that we will obey. Deeper, 'freedom' means that human beings are essentially capable of collectively transforming their social life so that its governing principles make possible the type of individually self-determining existence that Kant theorizes abstractly. The 'essence' in question here is not an immaterial universal form. It is, on the contrary, a real potentiality of human beings. Such an understanding of essential freedom is the basis of Marx's philosophical foundations of historical materialism. Reflecting on the difference between humanity and other species Marx was led to the essential role of consciousness in distinguishing humanity. His conception of consciousness, however, is directly linked with the active processes by which human beings create and transform social relations. As he wrote, "the animal is immediately one with its activity. It does not distinguish itself from it .... Man makes his life-activity itself the object of his will and of 
his consciousness. He has conscious life-activity" (Marx, 1975a: 276). In other words, human beings do not simply behave or mindlessly enact social and cultural codes. Humans are capable of thinking about what they do. This capacity to think about what we do is the basis of possibility for becoming conscious of a contradiction between how we are acting now and how we could act more fully and freely in changed social conditions. Hence the capacity to take social and individual life as the object of consciousness and critically evaluate it against values that are asserted as principles but not yet institutionalized is the core of essential human freedom.

The evidence of the reality of this essential freedom is given by the millennia old histories of resistance to multiple forms of oppression. As Marcuse once argued in relation to the idea of an essential freedom, its 'truth ... is preserved better in human misery and suffering and the struggles against them than in the forms and concepts of pure thought"(Marcuse, 1968: 73.) What Marcuse means is that we cannot understand what misery and suffering are, much less comprehend the cause of resistance to it, if we do not judge the situation from the perspective of a real potential (essence) for free existence. Human misery and suffering is not simply explicable in terms of gross physical deprivation (although the world still abounds with examples of it) but must be linked to a deeper capability on the part of people (whatever their concrete identities) to determine their collective and individual horizons for themselves. If there were no real potential for self-determination what could be the deep ground of the real fights against 'misery and suffering' to which history bears witness?

To elaborate by way of answering this question, if a group is really oppressed then there must be some real aspect of themselves that is prevented from becoming manifest in their actual situations. If different groups can truly to be said to be oppressed (i.e. share a common identity as oppressed) then, whatever their concrete differences they must also share a human reality which allows their situation to be judged as identical. To be sure, particular differences are part of what is oppressed. Beneath these particular differences, however, there must also be presupposed a capacity on the part of the oppressed, whatever their concrete identity, to transform and redefine the institutional structures in which they live and to consciously (i.e. intentionally and freely) express themselves as they take themselves to be in their truth. This capacity for self-determination is the essential human freedom to which I referred above. Unless this universal capacity for self and social transformation is presupposed, then the very idea of oppression does not make sense. Consciousness of oppression means consciousness of not being able to make oneself in reality what one takes oneself to be essentially. But the 'essence' here is not a particular cultural difference but the universal human capacity for self-making and selftransformation. Without a sense of themselves as essentially free, no oppressed group could ever conceive of the concrete social situation being different, and therefore 
resistance would never arise. The reality of resistance, therefore, proves the reality of essential freedom; the multiple forms of resistance and the multiple groups that resist proves the concrete universality of this freedom that defines human beings as subjects, and not objects, of their own history. To be made the object of the instrumental designs of a self-interested class, group, party, etc., is, in the deepest sense, to be oppressed To overcome oppression, therefore, is to realize in action the essential freedom that makes the oppressed human, beneath the particular differences that define them as a specific identity or by which they define themselves.

Thus it is a contradiction in terms to refer to a people as being liberated from oppression by an agency which is not their own. Essential freedom is identical to subjecthood as conscious agency. Hence, the oppressed can only define their reality freely if the work of liberation from oppression is also their own act. Otherwise they would be in the contradictory position of being free as subjects at the same time as they are the object of an external power determining for them what their future will be. ${ }^{3}$ In other words, where an oppressed people is said to be liberated by the agency of an external power, their reality is not liberation, but of passing from the service of one external power (the oppressor) to the service of another (the purported external 'liberators). In either case, the oppressed remain in a position of passivity and servitude.

Real freedom demands that the oppressed are able to prove to themselves that they are essentially free through new forms of conscious political activity in which essential freedom can be experienced in its extrinsic, concrete, and actual form. The oppressed must experience themselves as the subjects (agents) of their own liberation. One does not have to accept Marx's social philosophy and theory of revolution as a whole to recognize the truth in his claim that "self-emancipation" is necessary in order that the oppressed "succeed in ridding themselves of the muck of ages and become fitted to founding society anew" (Marx, 1975b: 60). No external power can give the oppressed this concrete experience of their own freedom because concrete freedom is collective self-activity in the process of institutional transformation.

This fundamental incoherence of the PLI would not be decisively resolved even in the unlikely event that stable liberal-democratic institutions can be constructed by the foreign power. Nor is it obviated if the intervening force is mandated to intervene by an (as yet non-existent) assembly of democratic nations, as theorized by Held (2004). Whether by illegal unilateral means or

legal collective means, the essential moment required for successful democratic transitions is lacking: the decision on the part of the oppressed population to no longer persist in oppression and thus to organize themselves to create new social relations. This claim raises two important objections that must be answered.

${ }^{3}$ For a deeper examination of the metaphysical commitments which this conception of freedom makes, as well as for a defence against postmodern critiques of 'essentialism' and a demonstration of those critiques' normative and conceptual incoherence, see Noonan (2003). 
The first is a pragmatic objection which maintains that there are cases where the oppressed people are simply too weak and the oppressing power too strong for internal democratic movements to succeed. While in some rare and contingent cases this claim may be true, it does not follow that the solution to the essential problem (the structure of oppression under which the population exists) is for liberal nations to militarily invade and forcibly restructure that society. The solution to that sort of problem (for example, in Darfur) is to raise the issue to global public consciousness, make the oppressing power aware that the world knows what it is doing, and to organize solidarity movements that generate extrainstitutional democratic pressure on the ruling power (as, for example, the global antiapartheid movement, largely organized without the support of Western governments, did). The effects of such extra-institutional movements may be slower, but these effects will better lay the foundation for a lasting progressive change, precisely because they strengthen the self-organizing capabilities of the oppressed and ensure that the subsequent changes are in their social and political interests.

The second objection is philosophical and maintains that even where the process of change is internal, the ideas according to which the change takes place are essentially Western. To return to the historical example of India, a classical liberal might argue that British imperialism was necessary in so far as it introduced new individualistic values into caste society and thus was the essential condition for the subsequent emergence of liberaldemocracy in India. This objection suffers from two problems. First, it ignores internal normative resources for social transformation (Sen, 1999). That is, it rests upon the onesided caricature of non-liberal cultures discussed above. More importantly, however, it distinguishes between the values of social change and the power by which that change is brought about. In cases of democratic internal social transformation, however, this distinction cannot be maintained. The value and the process by which the value is realized coincide. The reality of the value of self-determination, for example, is precisely that different groups and peoples employ it in actual struggles for change against external authorities. That is, once a movement for self-determination emerges it becomes the material reality of that value such that it makes no sense to say that a non-Western people enacts a Western value when it struggles for the conditions of self-determination. The movement for self-determination is the value of self-determination. Thus India, to stick with that example, did not become a relatively stable liberal-democratic regime because the British exported parliamentary democracy but rather because the Indians themselves revolted against the colonial structures imposed upon them. To be sure, liberal-democratic ideas and institutions were adopted and tailored to an Indian reality. That fact proves that those ideas are not essentially 'Western' but human ideas whose efficacy is contingent upon their being taken up, used, and transformed by the indigenous population. 
In other words, the fact that certain ideas might have emerged 'first' in Europe does not means that they are therefore 'European' ideas. As Franz Fanon argued in this regard, "all the elements of a solution to the great problems of mankind have existed at one time or another in European thought. But the action of European man has not carried out this mission ... let us reconsider the question of the cerebral reality ... of all mankind, whose channels must be diversified, and whose message must be rehumanized" (Fanon, 1968: 314). Fanon's point is that the truth of ideas is not determined by the geography of their emergence, but their applicability to definite contexts of action. In other words, whatever specific institutional form(s) the democratic transformation of an oppressed society may take, if these institutions are to define a free society, they must be created by the collective efforts of the oppressed themselves. The PLI's conceptual incoherence is thus a function of its claim that in the case of non-liberal cultures the agency of the oppressed population can only be realized once a liberal power (or group of powers) has intervened and established itself as the power by which the agency of the oppressed is created and activated.

\section{Human Rights and Human Freedom}

The conceptual incoherence demonstrated above is a formal contradiction existing at the heart of the PLI. This formal contradiction is not its only problem, however. Its understanding of the content of a free society is equally problematic. Defenders of the PLI equate the institutions of developed liberal-democratic capitalism as the necessary and sufficient social conditions of human freedom. To conclude, I want to expose the social contradiction lying at the heart of the liberal understanding of the institutions of a free society.

The institutions of liberal-capitalist democracy are not identical to democracy and human freedom but historically specific institutions whose origin must be explained by reference to the struggle between the dominant economic class and the subordinate classes, sexes, races, and sub-groups initially excluded by the modern liberal-capitalist nation-state (Wood, 1995). The rights that form the conceptual foundation for the idea of human rights are the constitutional rights that defined the liberal-democratic capitalist nation-state. Just as a one-sided interpretation of the content of non-liberal cultures blocks understanding of internal resources for social transformation, so too an ahistorical and one-sided interpretation of human rights blocks understanding of their limitations as the necessary and sufficient framework for a positively free human society. Once we explore their historical origin and social implications, however, their essential limitations come to light.

Like the national constitutions upon which it is modelled, the United Nations's Declaration of Human Rights (UNDHR) places overwhelming emphasis on the traditional liberal civil and political rights: to private property and security of the person, freedom from arbitrary 
arrest and detention, the right to express one's beliefs without illegitimate interference and to participate in the politics. In short, the UNDHR articulates a global framework of liberal rights in abstraction from the particularity of national citizenship. As national constitutions frame the principles of national political legitimacy so too is the UNDHR the prototype of a framework of international political legitimacy (i.e. the criteria by which a nation can be recognized as belonging to Held's (2004) association of democratic nations). To be sure, civil and political rights represent a profound advance in the struggle against arbitrary political power, irrational hierarchies of status, and have thus served to advance formal equality between citizens. To the extent that they become the objects of struggle of indigenous political movements around the world they can be powerful tools in the struggle against oppression. But what they cannot do, even when coupled with the positive social and economics rights, is secure the material conditions for a democratic society and positive human freedom.

This argument will sound surprising to anyone who assumes an identity between liberalism and democracy and democracy and capitalism. Nevertheless, I contend that the form of democracy that has evolved from the liberal idea of rights in fact lacks the essential foundation of a genuinely democratic society- collective control over fundamental life-sustaining resources and the means of production of social wealth. Liberal democracy is not based upon the principle that all institutions in which the lifehorizons of people are determined must be under the control of the people whose lives are so determined. On the contrary, it is based upon the principle of limited popular power, and especially upon the limitation of popular power to the 'public sphere,' a sphere that has traditionally been interpreted as exclusive of the economic system. In the realty which we inhabit today, consigning the economic system to the private sphere means allowing the property rights of multinational corporations, not private individuals, to exercise unchecked power over the life horizons of the globe's inhabitants. The UNDHR does not contest this usurpation of control over the fundamental conditions of being alive and living freely, but rather facilitates it. As Teeple argues, "global corporate rights requires regionally or globally asserted civil and economic rights, and these rights in turn need to be guaranteed by nation states" (Teeple, 2004: 31). Since political rights are assumed to function only in the extra-economic public sphere, and social and economic rights are upheld only to the extent that they do not 'interfere' with the economy, they cannot in and of themselves form the basis of a democratic counter-weight to the totalizing drive of global capitalism to appropriate to itself whatever it is capable of bringing within the orbit of its property rights.

To insist upon the contradiction between the liberal value of the separation of political and economic power and the democratic value of collective control over all life-shaping institutions is not to be indifferent to the difference between constitutionally limited 
government and political dictatorship. There are degrees of freedom and liberal democracies are more free than arbitrary dictatorships. The key advantage of a liberal democracy, however, is that they make political organization, and therefore the elaboration of more deeply democratic demands, easier.(Rueschemeyer, Huber Stephens, and Stephens, 1992). In short, liberal democracy is nothing more (but also nothing less) than a plateau in the struggle for the social conditions of human freedom. However, the globalisation of capitalist economic dynamics has compromised the national foundations of liberal democracy and therefore the political efficacy of the rights that defined it. If that claim is true, then it follows that the liberal idea of human rights cannot be a sufficient basis for democratic resistence to globalization. It further follows that simply to insist on the enforcement of human rights in abstraction from support for local struggles to either defend or reclaim natural and social wealth from multinational invasion fails to understand the material conditions of human freedom that human rights supporters nevertheless claim to uphold.

A world of democratic societies (i.e. societies in which not simply the abstract political right to participate but in which the actual determination of social policy by interacting citizens defines the framework of social reproduction) cannot be immediately realized in the present because the current institutionalization of liberal-capitalist social morality is an obstacle to it. That does not mean that rights are nothing but illusory freedoms. On the contrary, it means that rights are partial freedoms and that the system of rights, including as it does the corporate right to own and control the world's life sustaining resources, contradicts the material foundations of human freedoms that make civil and political rights meaningful. Especially in so far as the system of human rights presupposes the formal separation of political and economic power it proves itself, at this point in history, inadequate to the job of satisfying the material conditions of a fully democratic society. It does make possible (in principle) the creation of liberal democracies out of dictatorships, but the two sides of the complex term 'liberal-democracy' are in tension with each other. As Ellen Wood explains, "capitalism made possible the redefinition of democracy, its reduction to liberalism. On the one hand there was a separate political sphere in which 'extra-economic'- political, juridical, or military- status had no direct implications for economic power, the power of appropriation, exploitation, and distribution. On the other hand, there now existed an economic sphere with its own power relations not dependent upon juridical or political privilege"(Wood, 1995: 234). That is, the operation of capitalist markets, unregulated, semi-regulated, or highly regulated, is necessarily coercive, determining as they do what will be produced, how it will be produced, how much it will cost, and therefore, by material implication, how lives will be led within it. Since no human rights as instituted in the present directly challenge this zone of economic power, or, indeed, even systematically explain its existence, they cannot form a sufficient foundation for democratic struggles against it. Unless those struggle develop and are 
successful, the future course of global development is towards more intense forms of servitude to capitalist market dynamics and not more democracy.

Thus the fundamental conflict in the world today is a conflict of freedoms. On the one hand there is the freedom of capital, in the form of multinational corporate right, to appropriate to its own use the totality of what there is to be appropriated. On the other hand, there is the freedom of human beings as active, potentially self-determining, but also needy beings, to collectively determine the structures within which individual life-projects are formed. The freedom of capital proceeds through the de-regulation of business environments and the subordination of local and national institutions of political power to the interests of multinational corporations all backed by the armed might of the US military. As Thomas Friedman said, "the hidden hand of the market will never work without a hidden fist ... and the hidden fist that keeps the world safe for Silicon Valley's technologies is called the United States Army, Air Force, and Marine Corps" (Quoted in McNally, 2002: 147). When Bush argues that 'freedom is on the march' in Iraq he is not talking nonsense but rather is referring to the freedom of capital. The freedom of humanity, on the other hand, proceeds through locally organized struggles to resist the appropriation of life-sustaining resources by the corporate right. Standing in solidarity with those sorts of indigenous movements for a democratic society is the best support that people in the West concerned about the inhuman life-conditions of others can provide.

\section{Conclusion: Universal Freedom and Solidarity}

Superficial appearances of identity notwithstanding, my critique of the PLI, the liberal understanding of the social conditions of freedom, and my emphasis on the need for an organic articulation between the universal idea of human freedom and indigenous practices and cultures is not an affirmation of cultural relativism. If one insists upon the link (as I do) between human freedom as a universal value grounded in our social-organic nature as reflective, active, and self-determining beings, and democracy, then many traditional practices rooted in asymmetries of power (sexual, generational, status, tribal, etc.), will prove ultimately incompatible with democratic social relations. Yet, if the work of freedom (self-transformation) is to be (as it must) the work of the oppressed themselves, then they must find their own way through these monumental complexities, just as the West has done (and continues to do, often very poorly). If the West, after 200 years of feminist struggle, for example, has still not resolved the problem of the oppression of women, why should any reasonable person expect that liberal platitudes will solve the same problem in cultures most Westerners do not understand? The point of my argument is not to lend uncritical support to culturally deep-seated forms of power asymmetry. The point, rather, is that a coherent understanding of the process of creating a free society entails respect for and confidence in the capabilities of different cultures to understand and work out for themselves the means of transforming those asymmetries. Anything less 
presupposes an essentially racist belief in Western superiority. The deep and enduring structures of oppression in the West make a mockery of such pretensions.

Moreover, as I noted earlier, those structural imbalances of power are much more likely to be exacerbated when a foreign invader presents itself as the agent of liberation. The good ideas and practices that democratic struggles in Western history have created will be demonized along with the armed forces, significantly delaying the hard political work of creating new democratic institutions. As the case of Iraq once again proves, armed force is always met by armed force. Invariably in such situations the invasion provokes resistence under the control of secretive armed cells whose survival depends upon being absolutely ruthless and undemocratic. While armed resistence to armed imperialist invasion must be regarded as legitimate by anyone who understands the normative commitments entailed by the idea of human freedom, its methods delay rather than promote the types of political organization that are necessary for popular liberation from oppression. Resources and energy are taken out of the mobilization of political intelligence and the collective transformation of institutions. Factionalism and political cannibalism are inevitable as is the widespread destruction of civilian life and life-serving infrastructure. Attempts to practically implement the PLI therefore undermine the development of just those political forces which could most efficaciously create new and free institutions.

Just as this argument is not blind to indigenous asymmetries of power, it is also not indifferent to the reality of the suffering of non-Western others under quite brutal regimes. It should be clear that I am not contending that comfortable Westerners should be blind to real suffering or indifferent to developing international movements in the service of democracy. In fact, solidarity is a key entailment of this critique of the PLI. Solidarity, however, must be rigorously distinguished from unasked for armed invasion of a sovereign nation. The criterion whereby they may be distinguished is clear. Solidarity is always and by definition a response to a request by the oppressed to stand with them and assist them in their struggle. Those who join in solidarity join a movement under indigenous leadership. Armed invasion, by contrast, is unilateral and usurpatious by its very nature, even if it were legitimated by a reformed UN Security Council or a new assembly of democratic nations. Solidarity can take many forms, from boycotting goods as in the global solidarity movement against apartheid to forming brigades of foreign fighters as in the case of the Spanish Civil War. No politically organized popular movement of the oppressed has ever, in my historical knowledge, requested a full-scale military invasion, complete with mass-murder bombing and subjection to arbitrary martial rule by the invading host. Indigenous supporters of invasions are almost invariably politically connected to the invader and stand to benefit materially from regime change. 
To conclude, it is clear that the PLI is conceptually incoherent. The nature of human freedom itself entails that groups of oppressed humans must organize and liberate themselves from their own oppression. Otherwise, the foundations of the experience of freedom necessary to construct free and democratic institutions (experience of themselves as the subjects of their own history) would be lacking. If my argument is sound then the people of the world should view with deep suspicion the idea of a 'human rights war.' The millions of people already killed by Western imperialism's various 'civilizing' missions in the eighteenth, nineteenth, twentieth, and now twenty-first centuries should be proof enough that human freedom is not a Western export and that it can only be created by people themselves operating from within the cultural frames that structure their history. Those cultural frames are not fixed realities but malleable structures which the people who live within them are capable of opening and transforming. Where solidarity is called for it can be given in such a manner as is requested by the oppressed themselves. But more than anything the oppressed people outside the Western world would benefit from the growth of democratic struggles within the West against the corporate interests that drive policy here and which produce so much suffering everywhere. 


\section{REFERENCES}

Ali, T. 2002. The Clash of Fundamentalisms. London: Verso.

Arendt, H. 1992. Lectures on Kant's Political Philosophy. Chicago: University of Chicago Press.

Fanon, F. 1968. The Wretched of the Earth. New York: Grove Press.

Goldman, L. 1971. Immanuel Kant. London: New Left Books.

Held, D. 2004. Global Covenant. Cambridge: Polity Press.

Ignatieff, M. 2004. The Lesser Evil. Toronto: Penguin Books.

Kant, I. 1987. Critique of Pure Reason. London: MacMillan.

McNally, D. 2002. Another World is Possible. Winnipeg: Arbeiter Ring Press.

Mill, J. S. 1975. On Liberty. New York: W.W. Norton.

Mills, C. W. 2003. From Class to Race: Essays in White Marxism and Black Radicalism. Lanham, MD: Rowman and Littlefield.

Marcuse, H. 1968. Negations. Boston: Beacon Press.

Marx, K. 1975a. "Economic and Philosophical Manuscripts of 1844." Karl Marx and Friedrich Engels, Collected Works 3, 1843-44. New York: International Publishers.

Marx, Karl. 1975b. The German Ideology. Moscow: Progress Publishers.

Marx, K. 1972. On Colonialism. New York: International Publishers.

Noonan, J. 2003. Critical Humanism and the Politics of Difference. Montreal: McGillQueen's University Press.

Noonan, J. 1997. "The Continental Divide: Marx and Mill on Progress in Europe and Asia." The European Legacy, Vol. 2, No. 6, pp. 1000-1011. 
Rueschemeyer, D., Huber Stephens, E., and J.D. Stephens. 1992. Capitalist Development and Democracy. Chicago: University of Chicago Press.

Sen, A. 1999. Development as Freedom. New York: Knopf.

Teeple, G. 2004. The Riddle of Human Rights. Toronto: Garamond.

Wood, E. M. 1995. Democracy Against Capitalism. Cambridge: Cambridge University Press. 